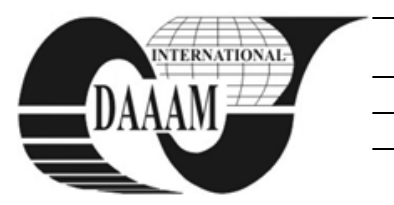

Annals of DAAAM for 2011 \& Proceedings of the 22nd International DAAAM Symposium, Volume 22, No. 1, ISSN 1726-9679 ISBN 978-3-901509-83-4, Editor B. Katalinic, Published by DAAAM International, Vienna, Austria, EU, 2011 Make Harmony between Technology and Nature, and Your Mind will Fly Free as a Bird Annals \& Proceedings of DAAAM International 2011

\title{
SELECTION OF THE BEST SOFTWARE FROM SEVERAL OFFERED FOR A PARTICULAR PURPOSE
}

\author{
TIRO, D[ragi] \& JUNUZ, E[mina]
}

\begin{abstract}
The paper explains the method of evaluating several possible variants, which are now commonly used in the selection of software available on the market. A drawback of this method is also explained. The new model that doesn't have the mentioned drawback is proposed. A simple case study of the evaluation based on the present and the new model is also given. This example illustrates the advantages of the proposed model.

Key words: software, selection, evaluation, method, model
\end{abstract}

\section{INTRODUCTION}

When a certain company or institution intends to buy software for a specific purpose, it can find several program packages on the market made by different software development companies. In this situation, it is necessary to select the most favourable one. Several methods may be used for the selection: DEA, MLOP, MWAF, ... (Fisher et al., 2004; Joro et al., 1998; Far et al., 2009). Yet, the most commonly used is the method of evaluating several possible variants (Pahl \& Beitz, 2007), that can be applied for different purposes including software selection.

\section{EVALUATION OF SEVERAL VARIANTS}

The first step in this method is to make a list of criteria (requirements, objectives) that software has to meet. Some objectives can have sub-objectives i.e. in order to meet a certain objective, it is necessary to meet several sub-objectives. This makes a hierarchical structure of objectives, called objectives tree. This structure can have several levels. (fig.1).

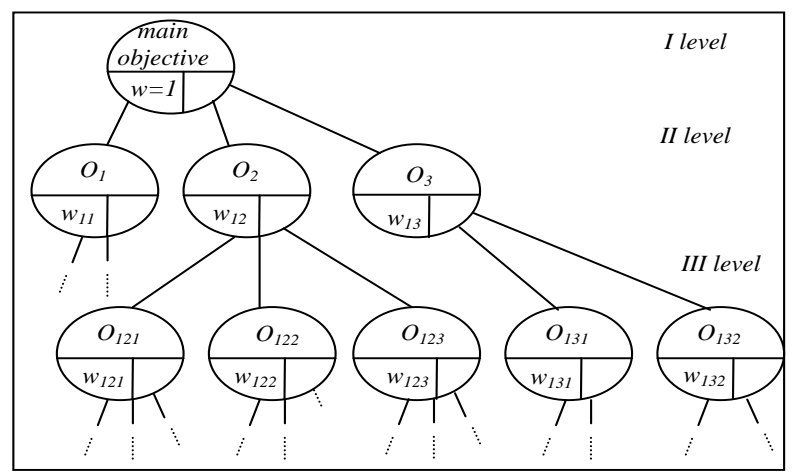

Fig. 1. Objectives tree with the levels

Objectives (criteria, requirements) don't have to have the same significance i.e. impact. Some criteria have higher and some smaller impact. This is indicated by the weighting factors $w_{i}$. Sum of weighting factors must be equal to 1 .

Each software being evaluated gets a grade $v_{i j}$ for each criteria, where index $i$ refers to criteria $i$, and index $j$ to software $j$ being evaluated. Value scale can be in range from 0 to 4 , from 0 to 10 etc. An adequate value scale can be used. Table 1 shows value scale from 0 to 4 .

\begin{tabular}{|l|l|l|l|l|l|}
\hline & $\begin{array}{c}\text { Absolutely } \\
\text { unsatisfac- } \\
\text { tory }\end{array}$ & $\begin{array}{c}\text { Just } \\
\text { tolerable }\end{array}$ & Adequate & Good & $\begin{array}{c}\text { Very } \\
\text { good } \\
\text { (ideal) }\end{array}$ \\
\hline$v_{i}$ & 0 & 1 & 2 & 3 & 4 \\
\hline$p_{i}$ & $0 / 4=0$ & $1 / 4=0,25$ & $2 / 4=0,5$ & $3 / 4=0,75$ & $4 / 4=1$ \\
\hline
\end{tabular}

Tab. 1. Value $v_{i}$ and relative value $p_{i}=v_{i} / v_{\max }$

When each sub-criteria that makes up a higher level criteria gets a grade, the value of hierarchically higher level criteria is calculated according to the following formula:

$$
p_{i j}=\sum_{k=1}^{s} p_{k j} \cdot w_{k}
$$

Where $p_{k j}=v_{i j} / v_{\max }$ - is a relative value of sub-criteria $k$ for software $j, w_{k}$ is a weighting factor of sub-criteria $k$ and $k$ goes from 1 to $s$, where $s$ is a total number of sub-criteria.

As an analogy, total weighted rating $W R_{j}$ for software $j$ is:

$$
W R_{j}=\sum_{i=1}^{n} p_{i j} \cdot w_{i}
$$

where $w_{i}$ is the weighting factor of criteria $i$ and $i$ goes from 1 to $n$, where $n$ is total number of criteria. Using formulas (1) and (2) it is possible to calculate weighted rating no matter how large is the objectives tree.

\section{DRAWBACK OF THE METHOD}

When a certain criteria gets a grade 0 , it means that this software is absolutely unsatisfactory with regard to this criteria. Such software should not be bought. However, if a certain criteria gets a grade 0, mathematical model (formulas (1) and (2)) can give a rather high grade. Sometimes, $W R_{j}$ of such software is rather high and sometimes even the highest of all evaluated ones. This can be illustrated by a simple case study.

\section{CASE STUDY}

Certain company intends to buy software for text scanning (to convert books and documents into electronic file) - OCR software. Four software packages $(j=1,2,3,4)$ are offered on the market. Criteria the software must meet are the following: $O_{I^{-}}$ it should have a user friendly interface; $O_{2}$ - it should have low price; $O_{3}$ - it should be able to recognize characters of different languages; $\mathrm{O}_{4}-$ it should be able to save text in different formats; $O_{5}-$ it should run on different operating systems. In order to simplify this process, we will assume that the criteria don't have sub-criteria. Each criteria has its weighting factor $\left(w_{1} ; w_{2} ; w_{3} ; w_{4} ; w_{5}\right)$. A theoretical discussion of methods for obtaining the weighting factors (Gonzalez et al., 2007; Tiro, 2010) is beyond the scope of this paper. Here we have: $w_{i}=0,25$; $w_{2}=0,2 ; w_{3}=0,25 ; w_{4}=0,2 ; w_{5}=0,1$.

Table 2 shows calculation of $W R_{j}$ using formulas (1) i (2). Software 2 has the highest $W R_{j}$. Therefore, this software should be bought. 


\begin{tabular}{|c|c|c|c|c|c|c|c|c|}
\hline & & $\begin{array}{l} \pm \\
\pm \\
\Sigma\end{array}$ & قa & $\ddot{8}$ & 产 & E. & 0 & \multirow{3}{*}{ 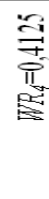 } \\
\hline & + & $\Sigma$ & $\ddot{b}$ & ă & $E$ & ấ & 0 & \\
\hline & & 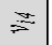 & $\sim$ & - & $m$ & - & 0 & \\
\hline \multirow{9}{*}{ ?z } & \multirow{3}{*}{$m$} & 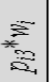 & $\frac{a}{a}$ & : & $\frac{5}{5}$ & $\vec{\sigma}$ & a & \multirow{3}{*}{ 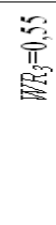 } \\
\hline & & $\Sigma$ & E & ב̆ & Ez & 3 & $\ddot{~}$ & \\
\hline & & $\approx$ & $m$ & - & $m$ & $\rightarrow$ & - & \\
\hline & \multirow{3}{*}{ C } & 咅 & $\ddot{a}$ & $\dddot{a}$ & 0 & 3 & है & \multirow{3}{*}{ 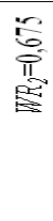 } \\
\hline & & ミ & $\rightarrow$ & E & 0 & - & E & \\
\hline & & $\cong$ & $\rightarrow$ & $m$ & 0 & $\rightarrow$ & $m$ & \\
\hline & \multirow{3}{*}{-} & \pm & قa & 8 & 总 & $\ddot{g}$ & $\ddot{g}$ & \multirow{3}{*}{ 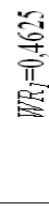 } \\
\hline & & $=$ & 2 & $\ddot{3}$ & IE & $a$ & 3 & \\
\hline & & $\equiv$ & $\sim$ & 一 & $m$ & - & $\sim$ & \\
\hline \multicolumn{3}{|c|}{ criteria } & 5 & $\sigma$ & $\sigma$ & 5 & 5 & \\
\hline \multicolumn{3}{|c|}{$\equiv$} & $\ddot{\sigma}$ & 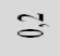 & gis & 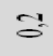 & $\vec{\sigma}$ & \\
\hline
\end{tabular}

Tab. 2. Calculation of $W R_{j}$ for software according to formula (2)

However, if grades in table 2 are analysed, it can be seen that $p_{32}=0$, which means that software 2 is absolutely unsatisfactory with regard to criteria $\mathrm{O}_{3}$. Software 2 is not able to recognize characters specific for different languages and thus, it got a grade 0 for this criteria. This means that software 3 should be bought even if $W R_{3}<W R_{2}$, because software 3 did not get a grade 0 for any of the criteria. Is it possible to propose a mathematical model that will avoid the mentioned drawback?

\section{PROPOSAL OF THE NEW MODEL}

The aim of this study is the new mathematical model for this method without the drawback.

Formulas (1) and (2) show a sum, so that criteria that got a grade $v_{i j}=0$ are "lost" among other criteria. If, instead of sum, we use product, we get formulas (3) i (4):

$$
p_{i j}=\prod_{k=1}^{s} p_{k j}^{w_{k}}
$$

or in the developed form:

$$
\begin{gathered}
p_{i j}=p_{1 j}^{w_{1}} \cdot p_{2 j}^{w_{2}} \cdot p_{3 j}^{w_{3}} \cdot \ldots \cdot p_{s-1 j}^{w_{s-1}} \cdot p_{s j}^{w_{s}} \\
W R_{j}=\prod_{i=1}^{n} p_{i j}^{w_{i}}
\end{gathered}
$$

This model (formulas (3) i (4)) doesn't have a previously mentioned drawback. If any of the criteria in objectives tree gets a grade 0 , then $W R_{j}=0$. Table 3 shows results of new model (formulas (3) i (4)) and it is clear that software 3 is the best.

\section{CONCLUSION}

Method of evaluating several possible variants is commonly used in the selection of software. Mathematical model shown with formulas (1) and (2) has a drawback. It is possible that the software that gets the highest weighted rating $W R_{j}$ has one or

\begin{tabular}{|c|c|c|c|c|c|c|c|c|}
\hline & & $\begin{array}{l}\bar{\Sigma} \\
\bar{\Sigma}\end{array}$ & 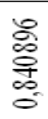 & 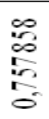 & $\begin{array}{l}\text { 令 } \\
\text { 。ू. }\end{array}$ & $\begin{array}{l}\infty \\
\infty \\
\infty \\
2 \\
\sigma \\
0\end{array}$ & 0 & $\begin{array}{l}0 \\
0 \\
0 \\
0\end{array}$ \\
\hline & $\tau$ & $\Xi$ & 3 & $\ddot{\sigma}$ & $\frac{2}{0}$ & $\tilde{\partial}$ & 0 & \\
\hline & & 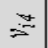 & $\sim$ & - & $m$ & 一 & 0 & \\
\hline \multirow{9}{*}{ 爱 } & \multirow{3}{*}{$m$} & $\begin{array}{l}= \\
\Sigma \\
=\end{array}$ & 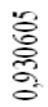 & 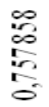 & 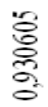 & $\begin{array}{l}\overline{8} \\
8 \\
0 \\
0 \\
0\end{array}$ & $\begin{array}{l}\overrightarrow{8} \\
8 \\
0 \\
0\end{array}$ & $\begin{array}{l}\overrightarrow{+} \\
\stackrel{+}{a} \\
0 \\
0\end{array}$ \\
\hline & & $=$ & 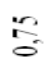 & $\ddot{\sigma}$ & $\ddot{8}$ & 2 & $\ddot{\sigma}$ & \\
\hline & & $\cong$ & $m$ & $\rightarrow$ & $m$ & $\sim$ & 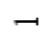 & \\
\hline & \multirow{3}{*}{$\sim$} & $\begin{array}{l}\bar{\Sigma} \\
\approx\end{array}$ & $\rightarrow$ & 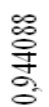 & 0 & $\rightarrow$ & $\frac{\text { 怘 }}{\text { 莺 }}$ & $\begin{array}{l}\prod_{0} \\
\text { 帒 }\end{array}$ \\
\hline & & $\approx$ & 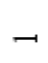 & 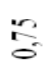 & 0 & 一 & 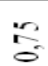 & \\
\hline & & $\cong$ & $\sigma$ & $m$ & 0 & $\tau$ & $m$ & \\
\hline & \multirow{3}{*}{-} & $\begin{array}{l}\bar{z} \\
= \\
=\end{array}$ & $\begin{array}{l}\stackrel{2}{\circ} \\
\text { 京 } \\
0 \\
0\end{array}$ & $\begin{array}{l}\infty \\
\infty \\
\infty \\
\vdots \\
0 \\
0\end{array}$ & $\begin{array}{l}\text { 令 } \\
\text { 。ू. }\end{array}$ & 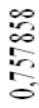 & $\begin{array}{c}\widetilde{\delta} \\
\tilde{\sigma} \\
\sigma\end{array}$ & \multirow{3}{*}{ 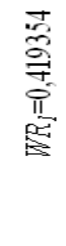 } \\
\hline & & $\Xi$ & 3 & $\ddot{\sigma}$ & $\ddot{\sigma}$ & $\ddot{\sigma}$ & 8 & \\
\hline & & $=$ & $\sim$ & - & $m$ & 一 & $\sim$ & \\
\hline \multicolumn{3}{|c|}{ criteria } & 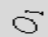 & $\tilde{\sigma}$ & ర & $\sigma^{2}$ & 0 & \\
\hline \multicolumn{3}{|c|}{$\cong$} & $\ddot{2}$ & $\tilde{\sigma}$ & है & of & $\overrightarrow{0}$ & \\
\hline
\end{tabular}
more criteria in the objectives tree that got a mark 0 - absolutely unsatisfactory.
Tab. 3. Calculation of $W R_{j}$ for software according to formula (4)

The new mathematical model that was proposed doesn't have mentioned drawback. It is the result of this study. It eliminates software that gets a grade 0 for any of the criteria.

In further research, it would be useful to develop software for application of this method using new mathematical model as well as to analyse application of this model for other evaluations.

\section{REFERENCES}

Far, B; Mudigonda, V \& Elamy A.H. (2009). A General Purpose Software Evaluation System, Informatica Vol. 33, No.3, pp. 261-270, ISSN 0350-5596

Fisher, D; Kiang, M; Fisher, S \& Chi R. (2004). Evaluating Mid-Level ERP Software, Journal of Computer Information Systems, Vol. 45, No.1, pp.38-46. ISSN 08874417

González-Pachón, J, \& Romero, C. (2007) Inferring consensus weights from pairwise comparison matrices without suitable properties, Annals of Operations Research, Vol. 154, No. 1, pp. 123-132, ISSN 0254-5330

Joro, T.; Korhonen P. \& Wallenius J. (1998) Structural Comparison of Data Envelopment Analysis and Multiple Objective Linear Programming, Management Science, Vol. 44, No. 7, pp. 962-970. ISSN 0025-1909

Pahl, G.; Beitz, W., Feldhusen, J. \& Grote, K.H. (2007). Engineering Design: A Systematic Approach. $3^{\text {rd }}$ Edition; Springer, ISBN 1846283183, Berlin

Tiro, D. (2010) The Correction of Weighting Factors' Values in the Evaluating Solution Variants, Proceedings of $21^{\text {st }}$ DAAAM International Conf., 20.-23.10, Zadar, Croatia, ISSN 1726-9687, ISBN 978-3-901509-73-5, Katalinic, B. (Ed.), pp. 975-976, DAAAM International, Vienna 